\section{$\underset{\substack{\text { hommes } \\ \text { \& migrations }}}{ }$}

\section{Hommes \& migrations}

Revue française de référence sur les dynamiques

migratoires

1316 | 2017

L'islam en Europe

\title{
Catherine Wihtol de Wenden (dir.), Atlas des
}

\section{migrations}

$4^{\mathrm{e}}$ édition, Paris, Autrement, 2016, 96 p., $24 €$

\section{Marie Poinsot}

\section{(2) OpenEdition}

\section{Journals}

\section{Édition électronique}

URL : http://journals.openedition.org/hommesmigrations/3837

DOI : $10.4000 /$ hommesmigrations.3837

ISSN : 2262-3353

Éditeur

Musée national de l'histoire de l'immigration

\section{Édition imprimée}

Date de publication : 1 mars 2017

Pagination : 195-196

ISBN : 978-2-919040-37-7

ISSN : 1142-852X

Référence électronique

Marie Poinsot, «Catherine Wihtol de Wenden (dir.), Atlas des migrations », Hommes \& migrations [En

ligne], 1316 | 2017, mis en ligne le 04 juin 2017, consulté le 23 septembre 2020. URL : http://

journals.openedition.org/hommesmigrations/3837 ; DOI : https://doi.org/10.4000/

hommesmigrations.3837 
migrants et des migrations, parfois à partir d'expériences ou de perceptions qui sont très anciennes dans un contexte migratoire qui a fortement ehangé.

tourageestorganisésansstructureat phabétique mais avec un agencement des notices respectant "une lecture de lespace migratoire mondial, et qui soit en cohérence avec l'organisation écono mique du monde les principates aires Eulturelles et sociopolitiques. Ils'agit des grands ensembles ou systemes migra toires régionaux, à l'intérieur desquels s'organisentet seréalisent les principau* flux de populations: I'Union europénne et ses bordures, l'Afrique septentrionate et le Moyen Orient, I'Afrique subsaha renne, l'Amérique du Nord, l'Amérique tatine, la Russie et l'espace post sovié tique, I'Asie du sud, l'Asie du sud Est, l'Asie te l'Est et l'océanie ". Plus qu'un état des lieux des recherches surces migra tions, cet ouvage propose pourchaque notice d'ouvir des perspectives et de nouveaux chantiers qui seront utiles ì tavenir pour déconstruire les discours simplistes surles flux migratoires, leurs eonséquences dans la vie quotidienne et les mouvements politiques des sociétés contemporaines. C'est done un dictionnaire à garder sous le coude pours'y référer fréquemment.

mènes migratoires et d'interroger de nombreuses "idées reçues qui, dans ce domaine sont tenaces ». Constatant que "les migrations ont pris ces dernières décennies une ampleur sans précédent et sont devenues une question clé pour l'équilibre mondial. Face à cela, les politiques nationales ou internationales se sont trouvées dépassées». Cet atlas puise ses données statistiques dans de nombreuses sources les plus récentes (ONU, Eurobaromètre, HCR etc.) qu'il interprète à travers des comparaisons, des évolutions chronologiques et démographiques pour mettre en perspective et dégager de grandes tendances. L'atlas se répartit en quatre chapitres: "Migrations, les grandes caractéristiques "; "L'Europe, un important pôle d'attraction"; " Le Sud en mouvement, Monde arabe, Afrique et Asie "; " Des 


\section{LIVRES}

enjeux politiques pour demain ". À travers la description des effets de la mondialisation sur les flux migratoires qui ne concernent que 3,5\% de la population mondiale, l'auteure démontre combien "les opinions publiques et les gouvernements peinent souvent à accepter certaines réalités, telle que l'objectif du vivre ensemble dans un monde cosmopolite, la nécessité de revisiter la citoyenneté ou encore l'influence des États de départ dans la gestion des migrations. Les politiques migratoires sont donc souvent en décalage par rapport à la réalité des flux".

Depuis plusieurs années, en effet, les mouvements migratoires se caractérisent par de nouvelles configurations: Sud-Sud, Nord-Nord, Nord-Sud, et pas seulement Sud-Nord. Les catégories de migrants se diversifient en terme de profils, de statuts, de stratégies migratoires à tel point que la distinction entre réfugiés et travailleurs se confond sociologiquement. Par ailleurs, les flux sont de plus en plus régionalisés au sein d'un même continent. L'Europe continue d'être un pôle attractif mais des pays émergents deviennent des pays d'accueil et les zones d'interdépendance provoquent des déséquilibres. Surtout, «les enjeux, tels que les perspectives démographiques mondiales, l'afflux de demandeurs d'asile, le changement climatique, l'urbanisation galopante de la planète autour de mégapoles du Nord et du Sud, la part des moyens d'information, vont tracer les grandes tendances des migrations futures $"$

Cet atlas apporte sur tous ces sujets complexes des données claires et argumentées. II propose des réponses chiffrées au grand débat qui secoue l'Europe au sujet de la crise des migrations : faut-il fermer les frontières? Si, selon l'auteure, le droit à la mobilité doit devenir un bien public mondial et si la réalité constatée des flux migratoires montre que les deux tiers de la population mondiale ne peut actuellement circuler librement, il est illusoire de penser que les politiques de contrôle des migrations, mises en place par des pays soucieux de préserver leur souveraineté sur leurs frontières et de répondre aux opinions publiques qui aspirent à la sécurité, pourront être efficaces. Elles contribuent, au contraire, à accroître le nombre des victimes de réseaux mafieux de passeurs et des violations des droits humains. Cet atlas constitue une ressource pédagogique pour faire avancer l'idée d'une gouvernance mondiale de l'immigration qui passe par une prise de conscience des apports des migrations dans de nombreux domaines pour les pays de départ comme d'installation, par des changements dans le regard porté sur les migrations et par l'invention d'un nouvel équilibre mondial. 